\title{
Public Speaking Tools ${ }^{1}$
}

\author{
Ricky Telg ${ }^{2}$
}

This publication about public speaking tools is the third of a three-part series about developing effective public speaking skills. This series also covers an introduction to public speaking and speech writing and types of speeches.

\section{Introduction}

When making a public speech, there are various tools at your disposal: vocal delivery, body language, visual aids, audience engagement, and the method of delivery. This publication provides some suggestions about how to make good use of these tools.

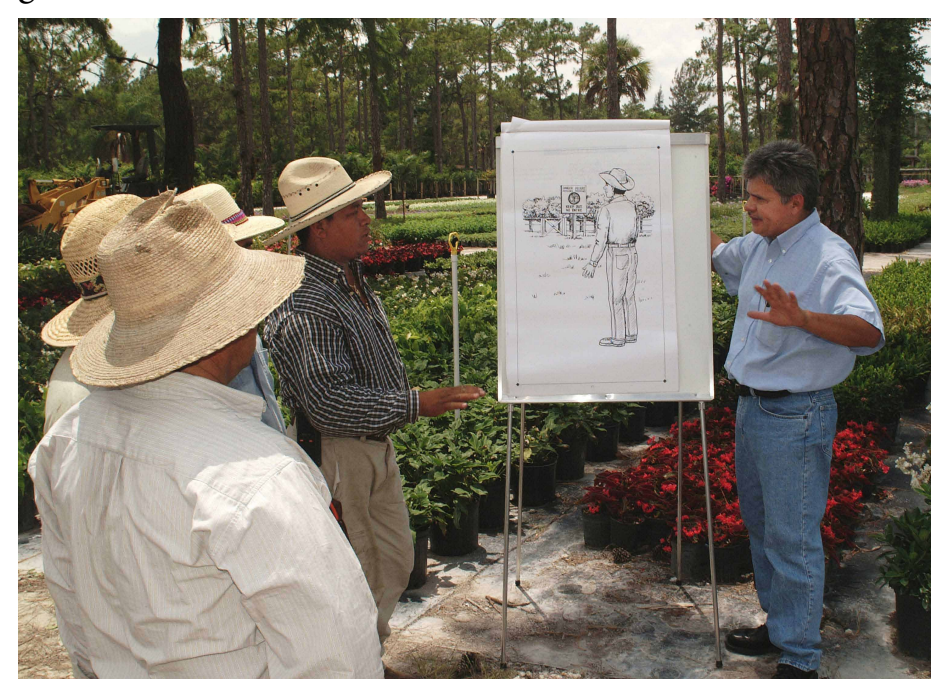

Figure 1. A graphic, photograph, or chart may be easier to understand than someone's vocal description of a topic.

Credits: Marisol Amador, UF/IFAS

\section{Vocal Delivery}

Vocal delivery refers to how you use your voice to communicate your message in a public speech. Speaking in a monotone manner, meaning there is no inflection or variety in your speaking patterns, tends to bore listeners. They tune out if your voice does not provide them with some enthusiasm or variety to help them key in to important sections of your speech. Ways to enhance vocal delivery include using variety in your volume, pitch, and rate, as well as articulating and pronouncing your words and eliminating verbal fillers.

Volume is the loudness or softness of your voice. You can speak loudly to call attention to important parts of your speech. Similarly, you may lower your voice almost to a whisper to emphasize other parts of the speech. The most important aspect of volume is that everyone in the room needs to be able to hear you, so do not lower your voice so much that people in the rear of the room cannot hear you.

Pitch is the high and low sounds of your voice.Vary your pitch to avoid a monotone delivery. However, the habit of inflecting up (raising the sound) at the ends of sentences and phrases is a pitch problem because it sounds like you are asking a question. Making everything you say sound like a question undermines your authority; it sounds as though you are asking for the audience's approval. You sound more assertive and confident when you lower your pitch and inflect downward.

1. This document is WC117, one of a series of the Department of Agricultural Education and Communication, Florida Cooperative Extension Service, Institute of Food and Agricultural Sciences, University of Florida. Original publication date August 2011. Visit the EDIS website at http://edis.ifas.ufl.edu.

2. Ricky Telg, professor, Department of Agricultural Education and Communication, Florida Cooperative Extension Service, Institute of Food and Agricultural Sciences, University of Florida, Gainesville, FL 32611. 
How fast or slow you talk is your speaking rate. While sprinting through your message may leave listeners behind, talking too slowly may bore them. Record your speech to determine if you speak too slowly or too quickly. If you talk fast, you run the risk of running your words together, making it difficult for your audience to understand you. You also may wish to insert strategic pauses to emphasize parts of the speech.

Articulation is the act of making distinct vocal sounds. As noted with rate, running your words together because you speak too fast is an element of bad articulation. Speak distinctly. Proper articulation helps your listening audience understand your words.

Also, properly pronounce words. For example, "picture" is pronounced "pic'-ture," not "pitch'-er," and "get" is pronounced "get," not "git." Pronouncing words incorrectly makes the speaker sound uneducated.

A verbal filler occurs when you use words or sounds such as "like," "you know," "uh," or "um" many times during your speech. These fillers break up the flow of your speech and cause listeners to pay attention to the fillers rather than your message. Fillers also make it seem as if you are not prepared for the speech. Some ways to overcome verbal fillers are to practice your speech until you can deliver it without resorting to verbal fillers, to slow down and allow yourself time to think about what you say before you open your mouth, and to become aware of the fillers you typically use. By becoming aware that you use the word "like" a lot, for example, you can teach your ear to listen for those times when you are tempted to use it, and you can slowly train yourself out of the habit of using that verbal filler.

\section{Body Language}

Your body is a valuable tool in a public speech. How you use body language influences what your audience thinks of you and how the audience understands your message. For example, you can emphasize points by pointing your finger, pounding your fist into your hand, or using facial expressions.

The first impression your audience members will have of you-even before you open your mouth to talk-is what they see. Your clothing and grooming should be appropriate for the occasion. For example, you would dress differently for a dinner speech than you would for a speech to a group of cattle producers as part of a beef cattle field day held by a county Extension office.
Your posture is important. Stand erect, but be comfortable, not stiff. Also, do not lock your knees in place because doing so can lessen blood circulation and cause you to pass out in the middle of your speech.

Throughout the speech, maintain eye contact with the audience. Slowly scan the room and talk to individuals as you present your speech. Do not read your notes word for word or look at the computer projection screen all the time. Audiences expect to be spoken to, and speaking involves eye contact.

Facial expressions can help you tell your story in meaningful ways. Your facial expressions should reflect what you say in your speech. If you are saying something about a happy occasion, your face should reflect that with a smile. Audiences respond positively to honest, sincere expressions.

Gestures involve movement of your arms, hands, and fingers. Use gestures to convey messages in a natural way. Be careful of overgesturing-using hand motions or moving your arms for no reason. Gestures done in a distracting way draw attention to your arms or hands, rather than to the message. Similarly, playing with your keys or change in your pockets can divert attention from what you are saying. Other distracting actions or gestures include adjusting your eyeglasses, keeping your hands behind your back, and crossing your arms or hands in front of you. You need to be aware of your entire body throughout the speech.

You may want to move around during the speech if you are able to. Sometimes you will not be able to move around much, for example, if the microphone is stationary. If you are free to move, do so in a way that does not distract from your message. Movement should be purposeful. As a rule, you should stand still except when you move for a particular reason or to stress an important point in your speech.

\section{Visual Aids}

Visual aids used in speeches are such things as objects, writing boards (chalkboards, dry erase boards, or smart boards), and computer-generated slides. Refer to Visual Communication (http://edis.ifas.ufl.edu/wc101) for more information about developing visual aids. When using visual aids, always maintain eye contact with the audience. This is especially true when using computer-generated slides, where the temptation is to read the words on the slide.

Visual aids are used for three main reasons: 
1. To seize viewers' attention and help them focus on major points. Sometimes it takes an eye-catching visual to grab the viewer's attention.

2. To translate words into meaning. A graphic, photograph, or chart may be easier to understand than someone's vocal description of a topic.

3. To get your point across. Use visual aids to help educate, inform, and persuade.

\section{Audience Engagement}

Engaging your audience helps your listeners feel as if they are part of the speech. You may not be able to engage the audience for every speech, but you should consider ways of interacting with the audience, such as asking questions, telling appropriate jokes, asking for feedback, and, if you are able to move around, walking around the audience.

\section{Method of Delivery}

For any type of speech, you can choose one of four methods of delivery: speaking from a manuscript, speaking from memory, speaking impromptu, or speaking extemporaneously.

Speaking from a manuscript means using a word-for-word script. Manuscript speeches are used when exact wording is required. Speeches given by political leaders are often done with a manuscript because the wording in manuscript speeches is carefully planned. Professional speechwriters often write manuscript speeches. The major disadvantage to a manuscript speech is that it is read to the audience.

The memorized speech is a manuscript speech committed to memory. This type of speech is used in oratory contests and on formal occasions. The speech is written out and then memorized word for word. It usually is best to have an outline of your speech in front of you in case you forget what comes next. It may take many days or weeks to commit the speech to memory, so it is always best to begin preparation for this speech delivery method far in advance.

An impromptu speech is unpracticed, spontaneous, or improvised. This type of speech is sometimes called "off the cuff" and usually involves little or no time to prepare. Impromptu speeches are usually given in emergency situations, such as when a scheduled speaker is unable to attend. If you are called upon at the last minute to give a speech, following are some ways to make the impromptu speech effective:
- If time is available, organize your ideas into an introduction, a body with three to five main points, and a conclusion.

- Jot down some short notes to help guide your speech.

- Act confident. Do not tell the audience that you do not know what you are going to say. The person in charge has asked you to deliver the impromptu speech because that person believes in you. Take reassurance in that.

- Be brief. This helps you avoid rambling.

- Draw on your experiences to help illustrate the points.

- Take a deep breath and focus on the topic.

The preparation required for an extemporaneous speech is between that needed for a memorized speech and an impromptu speech. Speaking extemporaneously requires considerable preparation before the speech is given, but the speaker waits until the actual presentation to select the exact wording of the speech. This type of delivery is frequently used on public speaking occasions because the speaker can be spontaneous and more conversational with the audience. Note cards of major and supporting points or an outline of key words and phrases can be used for extemporaneous speeches.

\section{Additional Information}

DiSanza, J. R., \& Legge, N. J. (2005). Business and professional communication: Plans, processes, and performance (3rd ed.).Needham Heights, MA: Allyn \& Bacon.

Hamilton, C. (2012). Essentials of public speaking (5th ed.). Belmont, CA: Wadsworth Cengage Learning.

Koch, A. (2007). Speaking with a purpose. Needham Heights, MA: Allyn \& Bacon.

O’Hair, D., Rubenstein, H., \& Stewart, R. (2007). A pocket guide to public speaking (2nd ed.). Boston, MA: Bedford/St. Martin's. 